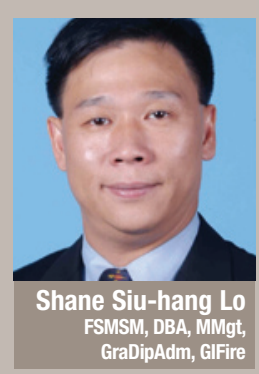

is deputy chief fire officer of the Hong Kong Fire Services Department

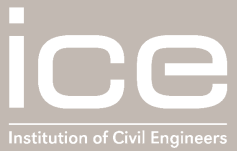

\title{
Fire fighting in high-rise buildings: the role for engineers
}

\section{This paper aims to give engineering professionals a better} understanding of the role and challenges facing fire services departments in enforcing fire safety and tackling towering infernos. In Hong Kong, where over seven million people live in high-rise buildings, the government has been injecting significant resources to address fire risk from educational, enforcement, economic, emergency and - crucially - engineering perspectives. The result is that overall fire risk is being comprehensively addressed for the benefit of both the community and fire fighters.

Hong Kong has an average population density of 6330 people per $\mathrm{km}^{2}$, making it one of the most densely populated cities in the world. This is achieved by most of its 7.2 million citizens living, working and even spending their leisure time in highrise buildings. It is not uncommon for more than 1000 people to be in a single high-rise building, entailing fundamental and critical concerns for fire safety.

This paper aims to give engineering professionals a better understanding of the role of the Hong Kong Fire Services Department (HKFSD) in enforcing and improving the fire safety of buildings, as well as the challenges and general opera- tional procedures of fire fighters when battling a towering inferno. The aim is to help engineers improve high-rise building design and construction for the benefit of the people who live in them as well as the fire fighters who protect them.

\section{Building safety role of fire fighters}

The HKFSD is built upon a mission to protect life and property from fire or other calamity in the territory through the delivery of fire fighting, rescue and ambulance services. It also formulates and enforces building fire-safety provisions in collaboration with other

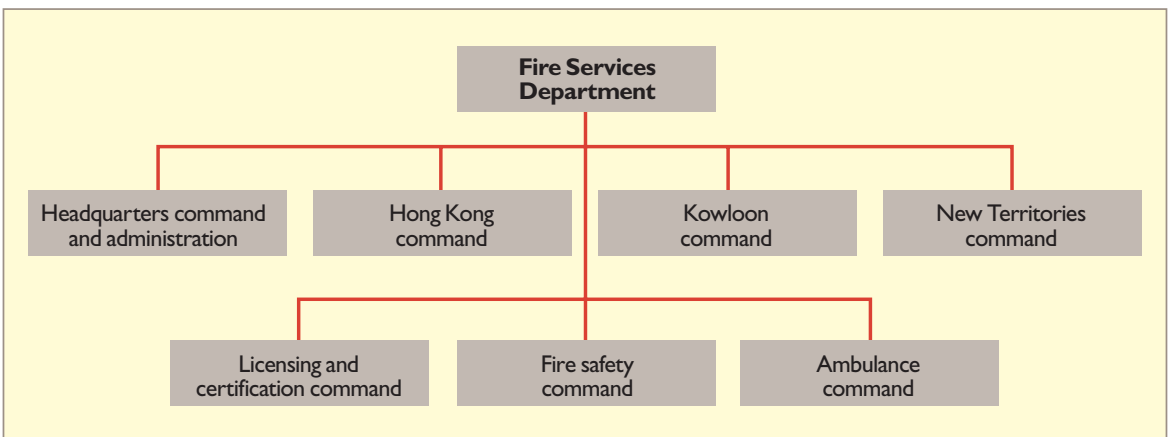

Figure 1. The 9400-strong Hong Kong Fire Services Department is structured into seven commands 


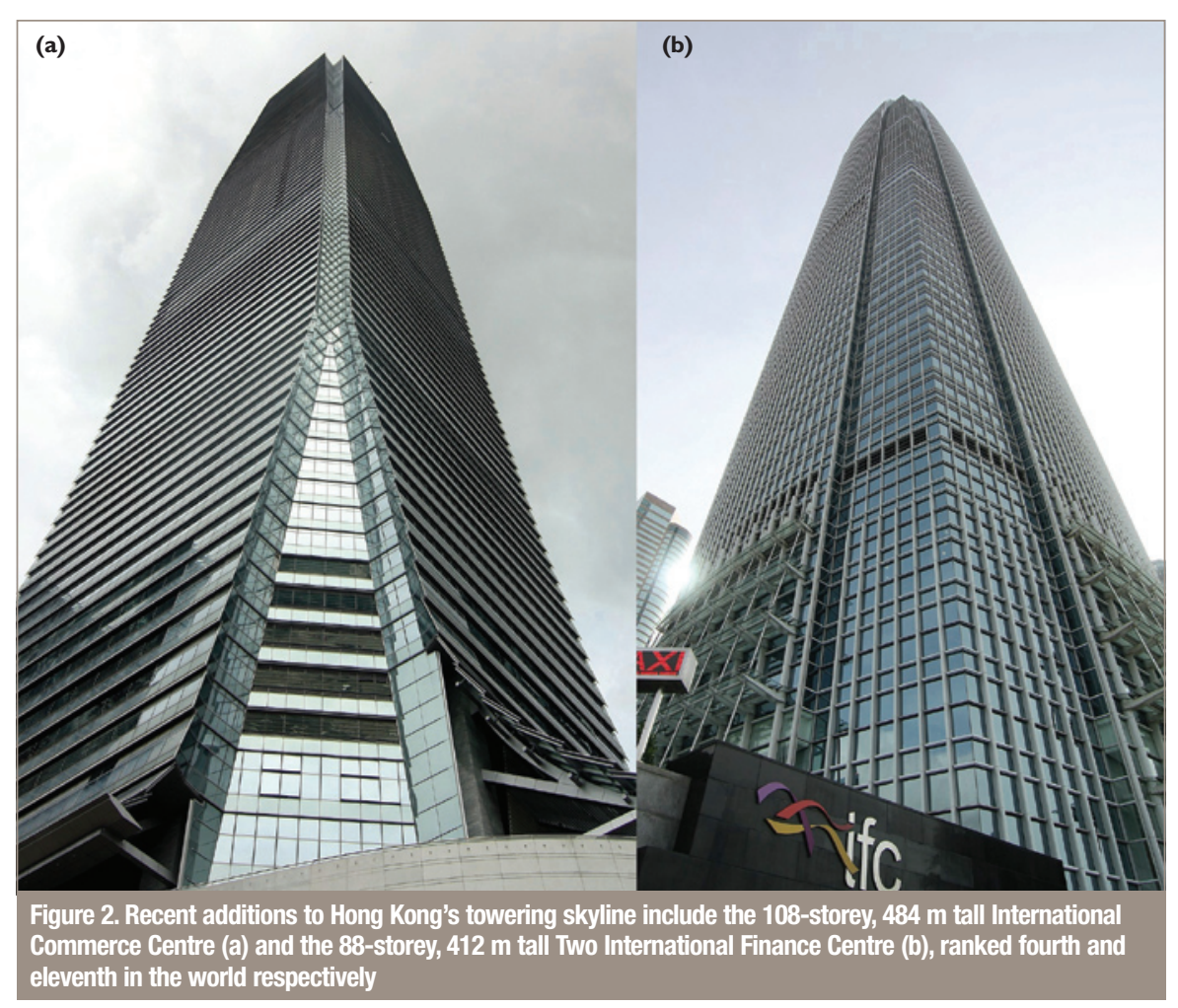

government departments and gives fire protection advice to the public. With around 9400 staff (including 8792 uniformed staff and 630 civilian staff), the organisation comprises seven commands: licensing and certification, fire safety, ambulance, headquarters and the three fire operational commands (Figure 1).

Insofar as stipulation and enforcement of building fire-safety standards are concerned, the HKFSD generally works under statutory powers conferred under the Fire Services Ordinance (HKG, 2004) and the Buildings Ordinance (HKG, 1997a), with a focus on active building fire-safety protection. Active protection refers to the provision of fire service installations and equipment for fire detection and suppression within buildings. Common fire service installation provisions for high-rise buildings include automatic sprinkler systems, fire detection systems and fire hydrant/hose reel systems as specified in the Code of Practice for Minimum Fire Service Installations and Equipment (HKFSD, 2005), first published in 1964.

The fire code is under constant review and is updated to keep pace with the latest developments in the building industry and fire engineering science. Key revisions include the mandatory requirement in 1973 for automatic sprinkler systems for new commercial buildings over $30 \mathrm{~m}$ high, which was extended to all new commercial buildings irrespective of height in 1987. The requirement for visu-

With regard to passive building firesafety protection, the fire code aims at securing the structural safety of the building and covers

adequate provision of means of escape

- adequate provision of means of access for fire fighting and rescue (including vehicles)

- compartmentation within a building

separation between buildings

fire-resistant construction of buildings.

The enforcement authority is the Buildings Department.

\section{Challenges in high-rise fire fighting}

There is no globally agreed definition of what constitutes a high-rise building. The International Conference on al fire alarms was introduced in 1998.
Fire Safety in High-Rise Buildings says a high-rise is, 'any structure where the height can have a serious impact on evacuation'. The New Shorter Oxford English Dictionary describes a high-rise as, 'a building having many storeys,' whereas the Massachusetts General Laws define a high-rise as a building higher than $21 \mathrm{~m}$.

The Hong Kong building regulations do not provide a definition, so the building industry generally follows the 1987 definition added to the fire code. This states a high-rise is, 'any building of which the floor of the uppermost storey exceeds $30 \mathrm{~m}$ above the point of staircase discharge at ground floor level'. The definition covers a vast number of buildings in Hong Kong, not least the 108-storey, $484 \mathrm{~m}$ tall International Commerce Centre and the 88-storey, $412 \mathrm{~m}$ tall Two International Finance Centre, ranked the fourth and eleventh highest in the world respectively (Figure 2).

Clearly fire fighting in high-rise buildings compared to low-rise is more difficult and risky. Tasks such as locating and tackling the fire, the evacuation of occupants and effecting ventilation can become very different, complicated and challenging.

The level of challenge and risk generally varies directly with the building height and the complexity of internal layouts. Typical problems encountered in highrise building fires in Hong Kong include the following.

\section{Limited access and communications}

At present, the aerial fire appliance with the highest working height in Hong Kong is the $52 \mathrm{~m}$ turntable ladder. Though the fire-fighting jet from the ladder head of a fully elevated $52 \mathrm{~m}$ long turntable ladder can reach up to the 22nd floor of a normally designed building, external fire fighting becomes unworkable if fire occurs on floors beyond this level. Practically, fire fighting must rely on internal operation via staircases. The situation is further compounded with concurrent use of staircases in the opposite direction by hundreds of building evacuees (Lo et al., 2001).

As such, fire fighting in high-rise buildings is a physically demanding task as fire fighters have to perform strenuous activities such as climbing long flights 
of stairs with heavy equipment and conducting search and rescue for large numbers of occupants in multiple locations at different floor levels (Bush and Routley, 1996). They also have to wear heavy breathing apparatus and thick personal protective clothing, as well as enduring unusual physiological and psychological stress when working in an extremely hot, humid, smoke-filled and unfamiliar environment.

Command and control can be extremely difficult in high-rise building emergency operations as the radio communications can be disrupted by thick concrete walls, partitions and steel structures. In extreme cases radio transmission signals can be completely absorbed.

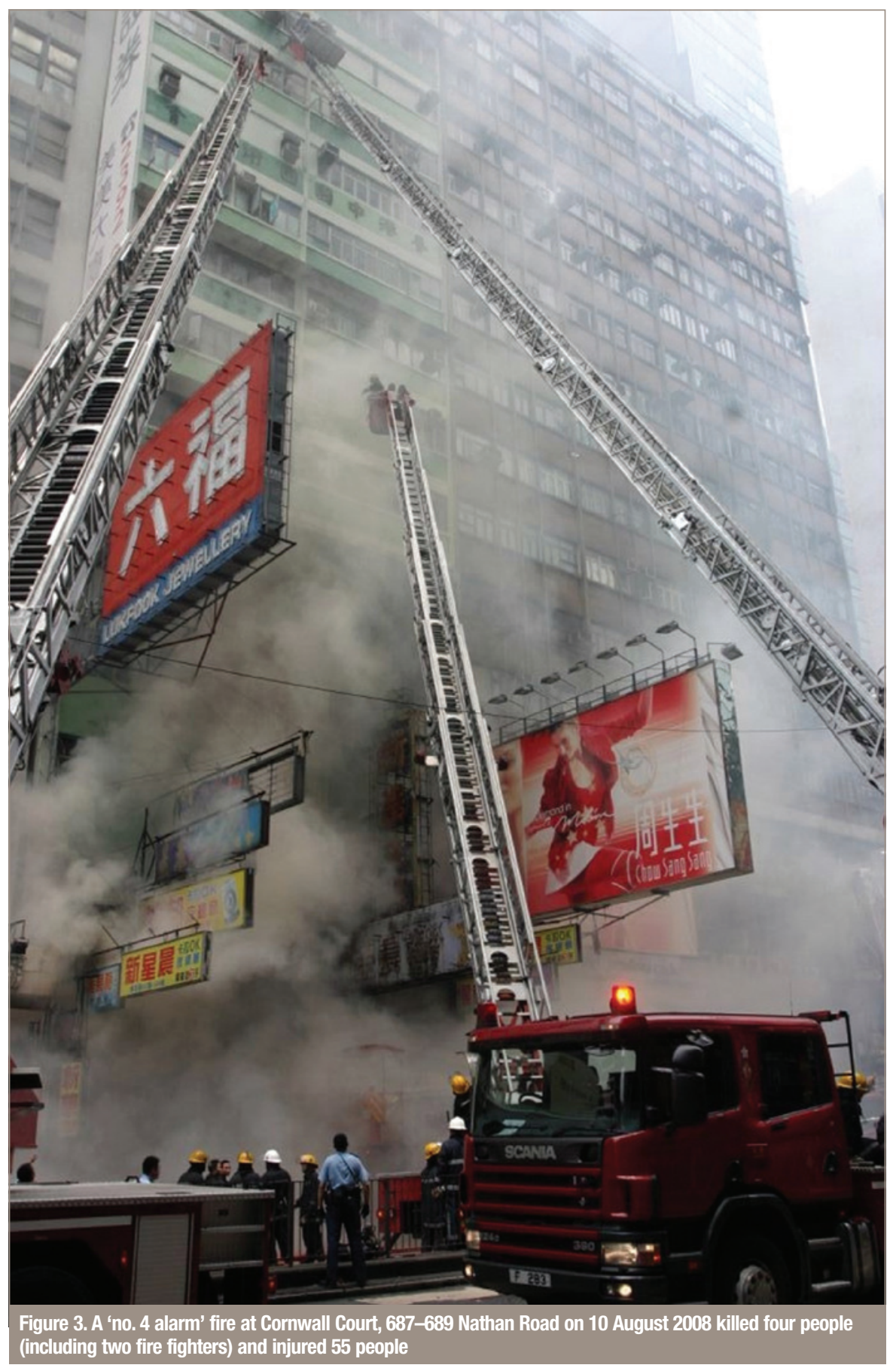

\section{More volatile fires}

With more space and more users, the quantity of combustible contents within a high-rise building is correspondingly larger. The consequential likelihood of a flashover also increases.

There is also a greater wind-driven effect in high-rise fires (Madrzykowski and Kerber, 2009). This effect is created where there are windows on opposite sides of the fire compartment or additional air is being fed to the fire from another source, resulting in unpredictable and rapid intensification of the burning rate, leading to temperature rises of 1100 ${ }^{\circ} \mathrm{C}$ within minutes. This can create havoc on the fire floor and poses a lethal challenge for fire fighters while attempting to control the fire and to advance toward the fire scene.

\section{System overload and failure}

Unauthorised building alterations such as breach of designed compartmentation may lead to unusual and unexpected fire spread and smoke travel. Fire-safety system design requires accurate calculation of the expected fire load and fire risk in the protected premises. Unauthorised change of use may also increase the fire load to the extent exceeding the design capability of the fire suppression system.

In high-rise building fires, the ability to contain and control the fire is increasingly dependent upon the ability of sprinkler systems and fire hydrant systems to deliver water to the fire area. If these systems fail, fire fighters are required to connect hundreds of lengths of fire hoses and transport bulky portable pumps upstairs in order to maintain effective fire-fighting water supplies. Such work requires great physical exertion and is often time consuming (Fong, 2000).

\section{Construction and demolition fires}

Although fire fighters may not have to face the problem of massive evacuation for fire incidents involving high-rise buildings under construction or demolition, they have to overcome other difficulties, such as the following.

There is no secure mechanical means of access in high-rise buildings during the construction or demolition 
stages. The only means of access to the fire scene is the staircases which are usually of reduced width or roughly built.

- The absence or malfunction of fireservice installation and water supply during the construction or demolition stages presents a great problem for fire fighters. Considerable manpower is required in laying hoses and placing portable pumping equipment at strategic positions for fire fighting.

- It is always difficult to identify one's whereabouts within a building under construction or demolition due to the uncertainty of building configuration. The problem is compounded if fire occurs during the hours of darkness.

- Many of the building elements are not in an intact and safe state. Death traps such as holes, crevices, obstacles and sharp edges can be found everywhere. Being unaware of such hidden dangers could result in risks to fire personnel.

\section{General operational procedures}

The continuing serious risk that highrise building fires in Hong Kong pose to the lives of occupants and well trained and equipped fire fighters is evidenced by three major fires over the past 15 years.
A 'no. 4 alarm' fire at Cornwall Court, 687-689 Nathan Road on 10 August 2008 killed four people (including two fire fighters) and injured 55 people (Figure 3).

- A ‘no.3 alarm' fire at QPL Industrial Building, 126-140 Texaco Road, Tsuen Wan on 22 May 2007 killed a young fireman and injured six other firemen (Figure 4).

- A 'no. 5 alarm' fire at Garley Building, 233-239 Nathan Road on 20 November 1996 killed 41 people (including one fire fighter) and injured 81 people (Figure 5).

To accomplish a high-rise fire fighting and rescue mission effectively and efficiently, fire fighters need to be well acquainted with operational procedures and execute them professionally. The pre-determined attendance schedule usually comprises a hydraulic platform for internal front-line fire fighting and rescue, a major pump for water supplies, a turntable ladder/snorkel for external fire fighting and rescue, a light/major rescue unit for breaking in and internal search and rescue and an ambulance for medical aid and assistance.

The course of key actions when responding to fire calls is briefly described in the next sections.

\section{Proceeding to fire scene}

While proceeding to a fire incident, the officer in charge prepares a tentative fire fighting plan with due consideration to the following.

Callers' information, in particular on persons reported and their reported locations as well as any involvement of dangerous goods or chemicals.

- The type of construction and special features of the building involved, life and occupancy risks.

- Access problems to the building such as stepped street, on-street parking, hawking activities or overhead obstruction.

- Fire hydrant locations and building fire-safety installation provisions.

It is obvious that the relevant information required for good pre-planning of fire fighting strategies must come from familiarity with the reported address on the part of the officer in charge and the responding crew. This illustrates the importance of knowing the topography and risks within one's station area through routine risk and familiarisation visits.

\section{Siting of appliances}

Upon arrival, fire appliances should be strategically sited, having regard to
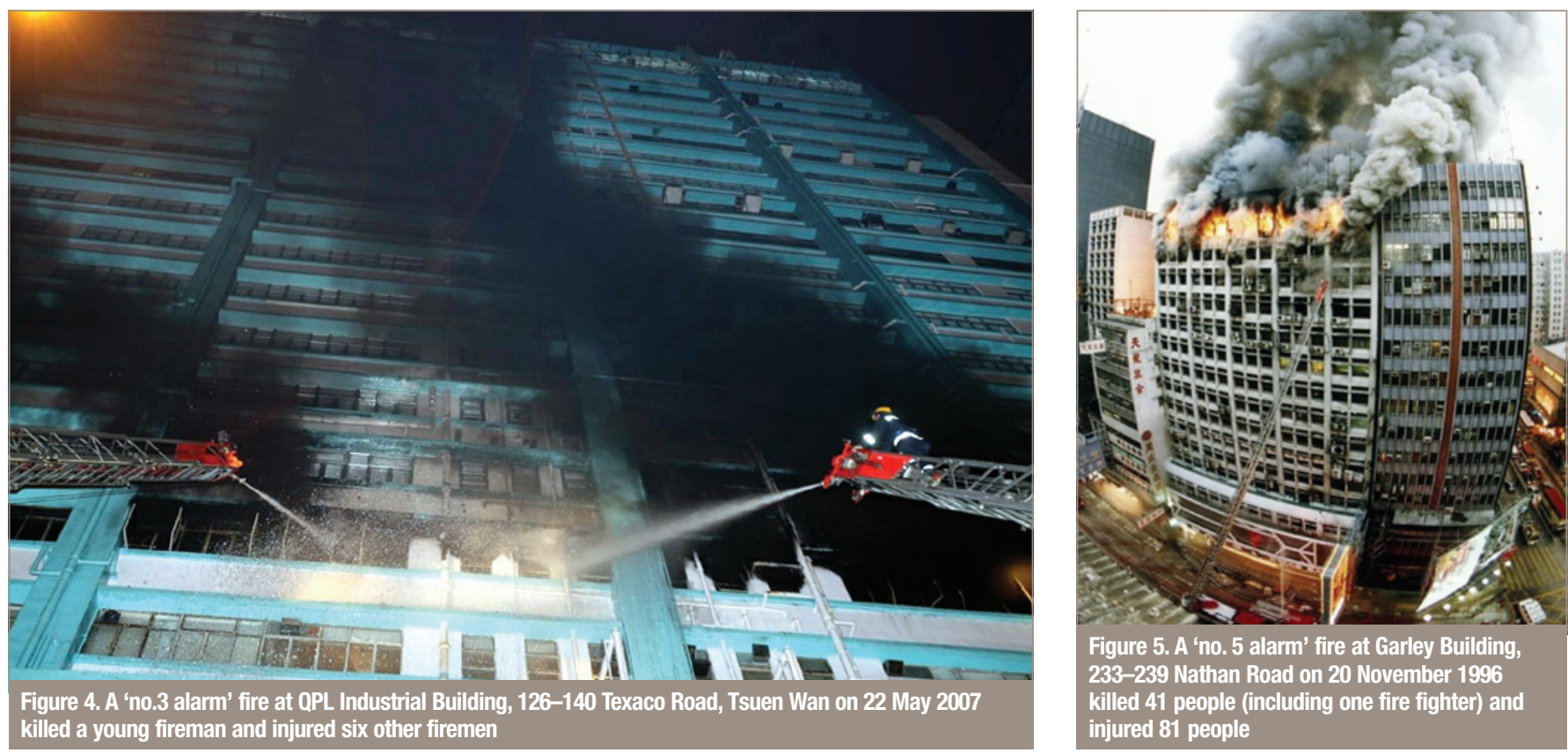
the following.

The building façade most favourable for external rescue and water supply should always be reserved for the turntable ladder/snorkel.

- The hydraulic platform should be sited near the main entrance of the building to facilitate prompt access.

- The major pump should be sited close to the nearest fire hydrant for obtaining water.

- The siting of initial attending fire appliances and laying out of fire hoses should not cause obstruction to reinforcing appliances.

- Fire appliances should be strategically sited to avoid potential damage caused by falling objects and debris.

- The ambulance should be sited as near to the scene as possible and be ready to leave, but should not in any way impede the fire fighting operation.

\section{Appraising and attacking fire}

Upon arrival at the incident scene, the officer in charge verifies the exact location of the fire scene, making an external survey to see whether smoke or fire is issuing from any part of the building and/or viewing the fire control panel and related facilities.

To enable tactical deployment of fire fighting resources, a forward staging area will be set up two floors below the fire floor. The real challenge for the fire fighters actually begins beyond this area.

Fire fighting hoses are connected from the building hydrant outlets and laid to the fire upstairs in order to absorb heat and reduce the temperature. At this juncture, fire fighters must make every endeavour to penetrate the burning area to attack the seat of fire.

\section{Preventing fire spread}

In the course of fire fighting, parallel action should also be taken to prevent fire spread through ducting, light wells, lift shafts, staircases and other openings between compartments and floors.

Extra effort to protect the staircases from fire spread and smoke penetration is necessary as the staircases are the principal escape route for occupants and access routes for fire fighters. Closing the smoke-stop doors and effecting roof exit ventilation helps keep these routes tenable.

\section{Search and rescue}

Human lives are the paramount consideration in any emergency operation. In the course of search and rescue operation, priorities are accorded to those people in the most imminent danger.

Building occupants would normally be escorted to street level through unaffected staircases or by using hydraulic platforms or the turntable ladder/snorkel. Should the staircase be blocked by smoke or high temperature, occupants would be led to the roof or refuge floor if provided. Sometimes it is viable to affect rescue via the roof of adjacent buildings.

\section{Incident command system}

To ensure effective and efficient command and control of all emergency operations at incident ground, HKFSD uses the 'incident command system' (ICS) (HKFSD, 1998) which is considered one of the best emergency management prac- tices worldwide.

ICS helps resolve most of the subsequent lawsuits related to accountability issues and has been widely implemented by many other national fire brigades. In some countries, the government budget approval criterion for emergency service agencies also requires, inter alia, the formal and explicit adoption of ICS.

\section{Operational preparedness}

To keep abreast of the ongoing development of fire science and building construction technology, HKFSD has been making every endeavour to foster and promote fire fighters' professional standards to sustain quality emergency service delivery to the community. Among other things, training on and learning from the best practices from counterparts outside Hong Kong are considered vital.

\section{Training}

Fires involving flashovers and backdrafts can cause serious injuries and fatalities. After several fire fighters lost their lives at incidents where flashover and backdraft had taken place, Sweden commenced a study of compartment fire behaviour training (CFBT) (CFBT Steering Group, 2000). The study integrated research work on fire behaviour, fire streams and ventilation within a structural fire fighting context. With proven success in operational efficiency and safety over decades, HKFSD introduced compartment fire behaviour training in 2001 (Figure 6).

Trainees are trained on the major aspects for safe and effective structural fire fighting operations, including

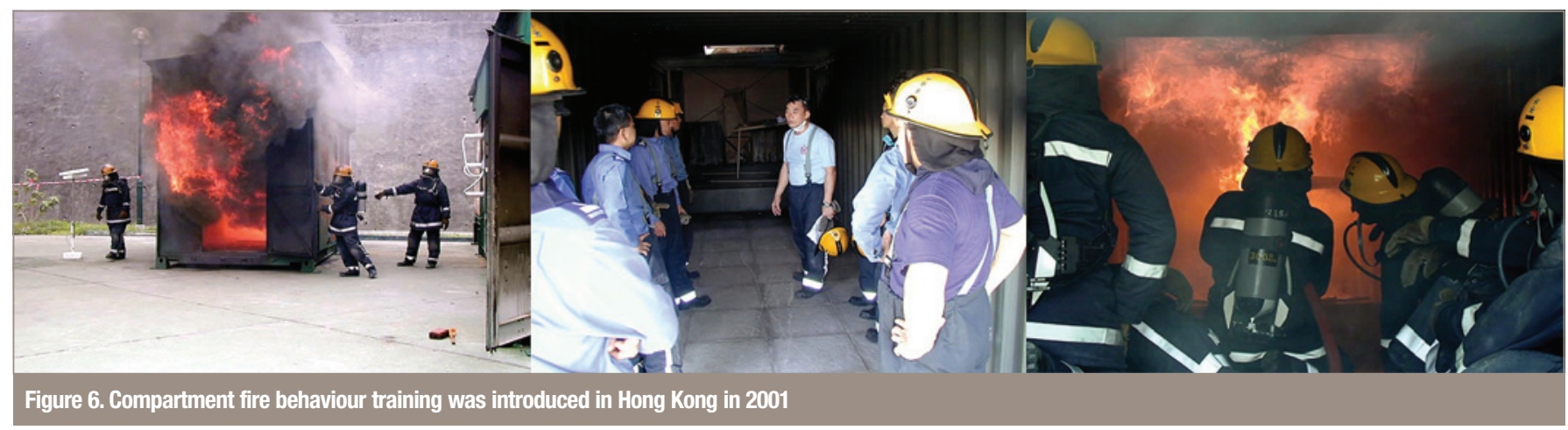


a solid understanding of how a fire develops within a compartment or structure

- the ability to 'read' fire behaviour indicators

- knowledge of how tactical operations affect fire development and environment inside the building

a high level of skill in the application of these concepts.

In addition to becoming a coretraining subject for all new-recruit fire fighters, annual refresher training on compartment fire behaviour training to all fire fighters has recently been implemented.

Fire-fighting safety and efficiency counts as much on expertise as practical experience. However, the decreasing trend of building fire calls over the decade and average retirement rate of more than 100 experienced fire fighters a year creates a knowledge management problem. To address this issue, the West Kowloon Rescue Training Centre was commissioned in 2006 to provide live fire and rescue training facilities under a safe and controlled environment. Facilities include the following.

- A simulated tunnel and chute system - for search and rescue training in confined spaces.

- A breathing apparatus training chamber called the 'maze' - to enhance search and rescue techniques under an oxygen-deficient, congested and/or smoke-logged situation.

- Live fire chambers - to provide various simulated structural fire situations (such as bars, hotels, domestic and industrial premises) with intense flame, heat and smoke as well as flashover.

\section{Learning best practice}

Each year, a number of Hong Kong fire fighters are sent abroad for international conferences for experience and knowledge sharing in the capacity of participants or speakers.

For example, a high-rise operation symposium organised by the Fire Department of New York discussed research work on wind-driven effects in high-rise building fires (Madrzykowski and Kerber, 2009), 'post radio' systems for securing reliable radio communication after 9/11 (McAllister, 2002) as well as the Local Law 5 New York regarding safety provisions for high-rise buildings under construction and demolition.

\section{Integrated risk interventions}

One of the best approaches to address the identified fire risks in high-rise buildings is through a combination of educational, engineering and enforcement interventions under the support of economic incentives and rapid emergency response (namely the '5Es' approach) (Homeland Security Department of USA, 2007).

\section{Education interventions}

Educational interventions include the education of the population at large with a view to changing knowledge levels, attitudes and behaviours of people. Usually, this requires an active approach because someone must do something to receive protection.

Following the tragic fire in 1996 at the Garley Building, HKFSD launched a pioneering fire safety ambassador scheme in 1997 to inculcate a community fire-safety culture and boost the fire-safety awareness of the general public. Under the scheme, participants are given general knowledge of fire behaviour, fire hazards and what to do in the case of fire.

Participants who successfully complete the training are appointed under a life term as fire safety ambassadors. They are expected to discharge their civic duties of

disseminating fire protection messages

- promoting fire safety awareness among citizens

- abating simple fire hazards by themselves or helping abate fire hazards by reporting to the fire department.

By the end of 2008, over 96000 fire safety ambassadors had been trained and appointed. Noting that reinforcement is important on a continual basis, the programme has been further strengthened by the implementation of an award scheme in 2002 and appointment of honorary presidents at district level since 2004.

\section{Enforcement interventions}

Following the Garley Building fire in 1996 and the Mei Foo Sun Chuen fire of 1997, which claimed a total of 61 lives, the Fire Safety (Commercial Premises) Ordinance and the Fire Safety (Buildings) Ordinance were enacted (HKG, 1997b; HKG, 2007). These two pieces of legislation aim at upgrading the fire safety standards (both active and passive) for old commercial buildings, composite buildings and domestic buildings built before 1987 as well as commercial premises not meeting modern fire safety standards.

By May 2010, 1652 prescribed commercial premises, 1409 specified commercial buildings and 356 old composite/domestic buildings had been inspected.

\section{Economic incentives}

In Hong Kong a HK\$700 million ( $£ 60$ million) building safety loan scheme was established in April 2001 to encourage and assist building owners to carry out building fire safety improvement work. The loan scheme is operating on a revolving capital basis and the interest rate is set at a no-gain-no-loss principle.

The normal loan repayment period is 36 months. However, owners in financial difficulty may apply for interest-free loans, a loan repayment period extension to 72 months or even an unspecified repayment period until the transfer of title of the property.

\section{Emergency response}

The fourth of the ' $5 \mathrm{Es}$ ' is rapid emergency response, as set out in the previous sections.

\section{Engineering}

The upward trend in building heights will no doubt continue, not only in Hong Kong but in most cities around the world. However, the traditional prescriptive fire-safety approach may not be sufficient for such buildings, given the potential inadequacies of standard fire 
safety installations, the vast numbers of building occupants and the unusually long vertical travel distances for access and escape.

The fire-engineering approach to building design that emerged in the mid 1980s has become a viable alternative to prescriptive building fire safety requirements. Irrespective of which approach used, the prime concerns from a fire fighter's operational perspective are

appropriate and adequate fire service installations

a enabling environment for launching a fire attack

- efficient means of access and escape (Zhao, 2001).

Connected to this, the proactive consideration and voluntary materialisation of the following safety provisions by engineering professionals are essential and critical.

- Public address system to enable evacuation in a controlled manner and to enhance the pre-movement time before evacuation by keeping occupants informed of their necessary actions during a fire situation.

- Pressurised staircases to reduce smoke-logged conditions in staircases resulting from 'stack effects' so that a safe means of escape for occupants and access for fire fighters can be maintained.

- Auto-recall lift system to prevent building occupants using lifts in the event of any fire situation.

- Refuge floors to serve as a place of rest for evacuating occupants and to facilitate the establishment of a forward staging area and/or command post by fire fighters.
Independent fire fighting and rescue staircase (containing lift and stair) to enable fire fighters to discharge their fire fighting and rescue duties safely and efficiently.

- Radio-telephone repeating facility (such as a leaky-coaxial installation) to enable a robust and reliable radio communication link for the effective command and control of all emergency operations at the incident level.

- For high-rise buildings under demolition, implementation of expedient fire safety measures similar to those contained in the FSD circular letter no.2/2008 (Fire Protection Measures in Construction Site) so that reliable water pumping and/or relaying facilities can be made readily available for fire fighting.

\section{Conclusion}

Hong Kong has been very fortunate in that there have not been many serious fire incidents in high-rise buildings. Generally the region has been able to limit the effects of fire through safer building design, unrelenting enforcement efforts on building fire-safety improvement work and defective fire service installations, and quick response to fire calls.

Looking back through the years, both fire fighters and engineering professionals have achieved much in making the built environment less susceptible to the effects of fire.

While inbuilt fire protection provisions may never be used during the lifespan of a building, these are costeffective essentials as prevention is better than cure.

Being mindful of complacency over its past achievements, the government is continuing to work together with fire fighters and engineering professionals to make Hong Kong a safer place to live, work and visit.

References

Bush R and Routley JG (1996) Special Report: Operational Considerations for High-rise Fire fighting (FEMA 082). Federal Emergency Management Agency, Washington DC, USA

CFBT (Compartment Fire Behaviour Training) Steering Group (2000) Guidance and Compliance Framework for Compartment Fire Behaviour Training, Fire Service Manual - vol. 4: Fire Service Training, The Stationery Office, UK. Fong NK (2000) Reliability study on sprinkler system to be installed in old high-rise buildings. International Journal on Engineering Performancebased Fire Code 2(2): 6I-67.

HKFSD (Hong Kong Fire Services Department) (1998) Incident Command System, F.S. Manual (Ops) part III Command and Communication. HKFSD, Hong Kong.

HKFSD (Hong Kong Fire Services Department) (2005) Codes of Practice for Minimum Fire Service Installations and Equipment and Inspection, Testing and Maintenance of Installations and Equipment. HKFSD, Hong Kong.

HKG (Hong Kong Government) (1997a) Buildings Ordinance, Laws of Hong Kong, chapter I23. Hong Kong Government, Hong Kong.

HKG (Hong Kong Government) (1997b) Fire Safety (Commercial Premises) Ordinance, Laws of Hong Kong Chapter 502. HKG, Hong Kong.

HKG (2004) Fire Services Ordinance, Laws of Hong Kong, chapter 95. Hong Kong Government, Hong Kong.

HKG (Hong Kong Government) (2007) Fire Safety (Buildings) Ordinance, Laws of Hong Kong Chapter 572. HKG, Hong Kong.

Homeland Security Department of USA (2007) Strategy for Community Risk Reduction - Pilot Student Manual. Homeland Security Department of USA, USA.

Lo SM, Lam KC, Yuen KK and Fang Z (200I) A Pre-evacuation behavioural study for the people in high-rise residential buildings under fire situations. International Journal on Engineering Performance-based Fire Code 2(4): 143-152.

Madrzykowski D and Kerber S (2009) Fire Fighting Tactics under Wind Driven Conditions: Laboratory Experiments. National Institute of Standards and Technology, Gaithersburg, USA.

McAllister T (2002) World Trade Center Building Performance Study: Data Collection, Preliminary Observations, and Recommendation (FEMA 403), Federal Emergency Management Agency, USA, 19.

Zhao $L$ (200I) A few issues on developing performance-based fire safety codes. International Journal on Engineering Performancebased Fire Code 3(4): $|4|-\mid 50$.

What do you think?

If you would like to comment on this paper, please email up to 200 words to the editor at journals@ice.org.uk. 